\title{
Cephalic Index among Nepalese Medical Students
}

\author{
Dr. Bipana Manandhar \\ Lecturer, Department of Anatomy, Kantipur Dental College, Kathmandu, Nepal \\ Correspondence: Dr. Bipana Manandhar; Email: bips_123@hotmail.com
}

\section{ABSTRACT}

Introduction: Cephalic index is race and sex specific parameter. Morphology of all living beings undergoes changes in varying degrees during their life and the features are variable in the individuals of the same species.

Objective: To measure the head size of the Nepalese medical students of both sexes between 18 to 24 years of age, to determine the different head type and to explore the distribution of cephalic index by ethnicity.

Materials \& Method: Materials used were a Spreading caliper and a measuring scale. The method used for assessing cephalic index was Hrdlicka's method.

Result: The result showed that the majority of the medical students of Nepal Medical College had typical Brachycephalic head type.

Conclusion: The dominant type of head shape revealed was brachycephalic and the least common head type as Dolicocephalic in Nepalese medical students of all the three ethnic groups namely Brahmin, Newar and Chettri.

Keywords: brachycephalic, cephalic index, dolicocephalic, hyperbrachycephalic, mesocephalic

\section{INTRODUCTION}

The word anthropometry is derived from a Greek word refers to measurement of the human individual (Anthropos-man, Metron-measurement).' Cephalometry is the branch of anthropometry in which dimensions of head and face are measured. Cephalometric results are used in pediatrics, forensic medicine, plastic surgery, oral surgery, dentistry and diagnostic comprehension between patient and normal populations. ${ }^{2}$

Cephalometry is an important tool for an anthropologist and forensic expert for identification of the racial differences, gender differences and comparison of changes between parents, offsprings and siblings to a great extent for the facial reconstruction of disputed identity. Cephalometry continues to be the most versatile technique in the investigation of the craniofacial skeleton because of its validity and practicality. The study is carried through the measurement of distances between significant structures. Comparison of measurements with the standards for the same age, race and sex is a valuable tool for diagnosis, treatment monitoring and prediction of orthodontic treatment. ${ }^{3}$
Cranial dimensions are not stable during earlier years of life due to further development such as closure of anterior and posterior fontanelle but are stable overtime (between 20-80 years). ${ }^{4}$ On the basis of above factors, anthropometric studies are conducted on the age, sex, caste and racial groups in certain geographical zones. ., $^{5}$

Cephalic index was first identified by Swedish professor of Anatomy; Anders Retzius. Cephalic index is an important parameter for deciding race and sex of an individual whose identity is unknown. The most important cephalometric parameters are height and breadth of head for the determination of cephalic index. ${ }^{7}$

Cephalic index is calculated as maximum head breadth/maximum head length $x$ 100. On the basis of cephalic index, the head shapes are classified into four international categories as Dolicocephaly, Brachycephaly, Mesocephaly and Hyperbrachycephaly. A cephalic index of 80 or more is called Brachycephalic or broad, a measurement between 75 and 80 is Mesocephalic, below 75 is considered Dolicocephalic or long and more than 85 is Hyperbrachycephalic. ${ }^{8}$ 


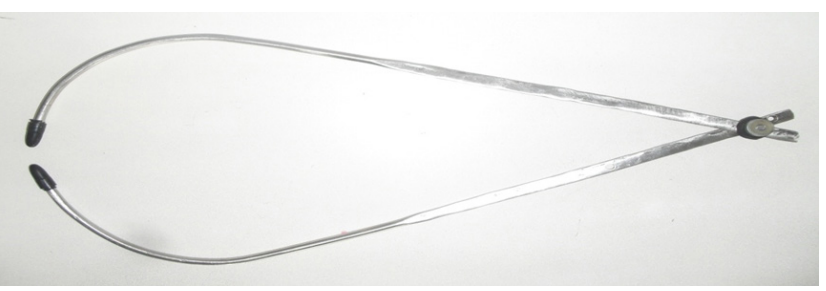

Figure 1: Spreading caliper

\section{MATERIALS AND METHOD}

The study was conducted in the Department of Human Anatomy, Nepal Medical College and Teaching Hospital, Jorpati, Kathmandu. Total 250 students were included in the study comprising of 124 males and 126 females. The students were categorized into three different castes namely Brahmin, Newar and Chhetri. The total number of Brahmin students was 84 consisting of 42 males and 42 females. The total number of Newar students was 83 out of which 41 were males and 42 were females and the total number of Chhetri students was 83 consisting of 41 males and 42 females. Students with normal craniofacial skeleton were included in the study. Students with deformities of cranial bone, vitamin D deficiency, fluorosis, metabolic disorders and previous history of craniofacial trauma and craniofacial surgery were excluded.

Materials used:

1. Spreading caliper: A device for measuring the head length and head breadth with two rounded tips to touch the cranial points.

\section{Measuring scale}

The students were informed about the procedure and consent was taken prior to measurement. In this study head length and head breadth were measured on medical students of age group of 18-24 years. The method used for assessing cephalic index was Hrdlicka's method. ${ }^{9}$ The head length (greatest antero-posterior

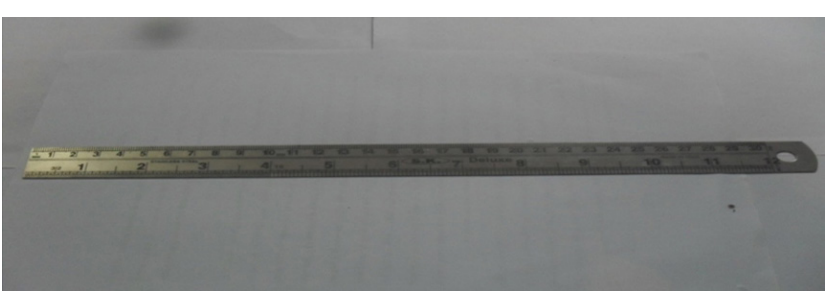

Figure 2: Measuring scale

Table 1: Normal range of cephalic index of different head shapes

\begin{tabular}{|l|c|}
\hline \multicolumn{1}{|c|}{ Head shape } & Range of cephalic index \\
\hline Dolicocephalic & $<74.9$ \\
\hline Mesocephalic & $75-79.9$ \\
\hline Brachycephalic & $80-84$ \\
\hline Hyperbrachycephalic & $>85$ \\
\hline
\end{tabular}

The data recorded were statistically analyzed using SPSS version 15. Student's t-test was used to evaluate the difference between the variables.

diameter) was measured with the help of spreading caliper from glabella to inion. The head breadth was measured as the maximum transverse diameter between two fixed points over the parietal bones between the two parietal eminences. All measurements were taken on the student sitting on a chair in a relaxed mood and head in anatomical position. The head length and breadth were recorded in centimeters. Cephalic index was calculated using the formula, Cephalic index = head breadth/head length $x$ 100. On the basis of international classification of cephalic index, head shape were classified on the basis of the range of cephalic index given below in the table. ${ }^{10}$

\section{RESULT}

The results from the Table 3 showed that the mean cephalic index of males as $80.51 \pm 5.26$ and in females as $81.96 \pm 5.62$, which was slightly higher than the males. Mean cephalic index of total students was $81.24 \pm 5.48$

Table 2: Descriptive statistics of cephalic index among the Nepalese medical students

\begin{tabular}{|c|c|c|c|c|c|c|}
\hline \multirow{2}{*}{ Caste } & \multirow{2}{*}{ Gender } & \multicolumn{4}{|c|}{ Head type (Number \& Percent) } & \multirow{2}{*}{ Total } \\
\hline & & Dolichocephalic & Mesocephalic & Brachycephalic & Hyperbrachycephalic & \\
\hline \multirow{2}{*}{ Brahmin } & Male & $9(21.42 \%)$ & $14(33.33 \%)$ & $14(33.33 \%)$ & $5(11.9 \%)$ & 42 \\
\hline & Female & $1(2.38 \%)$ & $14(33.33 \%)$ & $16(38.09 \%)$ & $11(26.19 \%)$ & 42 \\
\hline \multirow{2}{*}{ Newar } & Male & $9(21.95 \%)$ & $8(19.51 \%)$ & $17(41.46 \%)$ & 7 (17.07\%) & 41 \\
\hline & Female & $2(4.76 \%)$ & $11(26.19 \%)$ & $15(35.71 \%)$ & $14(33.33 \%)$ & 42 \\
\hline \multirow{2}{*}{ Chhetri } & Male & $2(4.87 \%)$ & $9(21.95 \%)$ & $20(48.78 \%)$ & $10(24.39 \%)$ & 41 \\
\hline & Female & $6(14.28 \%)$ & $14(33.33 \%)$ & $12(28.57 \%)$ & $10(23.80 \%)$ & 42 \\
\hline
\end{tabular}


Table 3: Descriptive statistics and significance of cephalic index between total male and female subjects

\begin{tabular}{|c|l|c|c|c|c|c|}
\hline \multirow{1}{*}{ Caste } & \multicolumn{1}{|c|}{ Gender } & N & Mean & SD & SE & p-Value \\
\hline \multirow{3}{*}{ Cephalic index } & Male & 124 & 80.51 & 5.26 & 0.47 \\
\cline { 2 - 7 } & Female & 126 & 81.96 & 5.62 & 0.50 \\
\cline { 2 - 7 } & Total & 250 & 81.24 & 5.48 & 0.34 \\
\hline
\end{tabular}

*Statistically significant at p-value $<0.05$

with standard error of 0.34 . This finding suggests that the majority of both males and female students of all three ethnicity belonged to Brachycephalic head type. The mean cephalic index of male and female students as $80.51 \pm 5.26$ with standard error of 0.473 and $81.9 \pm 5.62$ along with the standard error of 0.500 . p-value as 0.037 revealed that the mean cephalic index of male and female was statistically significant.The cephalic index between the three ethnicities was not statistically significant as p-value was 0.075 .

\section{DISCUSSION}

Different workers have studied the cephalic index in different populations and have reported different type of cranial characteristics. Since there is not much published data available on cephalic index of the Nepalese community the data presented in the present report can be useful for comparison among the racial differences.

In the present study, the predominant head type of all the medical students belonging to the three ethnic groups was Brachycephalic which was similar with the study conducted on the dental students of Showa University in Tokyo." The Brachycephalic dominancy was also observed in Gurung population of Nepal. ${ }^{12}$ This finding was also similar with the studies conducted on medical students of University of Ruhuna, Sri Lanka ${ }^{13}$ and on Kosovo-Albanian population. ${ }^{14}$ This finding was also consistent with the studies on individuals of Mumbai origin $^{15}$ and on Ogonis ethnic group of Nigeria. ${ }^{16}$
The present study finding was however not similar with the studies conducted on Mukarampur village Madhya Pradesh, India between the two dominant sub caste groups Dangi and Ahiwar ${ }^{17}$ and on students of Delta state university from three culture lines of Urhobo, Ibo and Edo. ${ }^{18}$ This finding was also not similar with Fulanis, Tangos and Teras people of North Eastern Nigeria ${ }^{19}$ and on the students of Brazil. ${ }^{20}$ Similarly this finding was not consistent with the studies conducted on medical students of Amp Nageswara Institute of Dental Sciences. ${ }^{21}$

\section{CONCLUSION}

The most dominant head shape was found to be Brachycephalic among medical students of Nepal Medical College consisting of the three ethnic groups namely Brahmin, Newar and Chhetri. The mean cephalic index of male and female students was statistically significant whereas the cephalic index among the three ethnic groups was statistically insignificant.

\section{Acknowledgement}

I would like to express my sincere thanks to Professor Dr. Shaligram Dhungel for his guidance. I would also like to thank all the students who volunteered to participate in research work. 


\section{REFERENCES}

1. Ulijaszek SJ, Kerr DA. Anthropometric measurement error and the assessment of nutritional status. Br J Nutr. 1999; 82(3):165-77.

2. Kumar M, Gopichand PVV. The study of cephalic index in Haryanvi population. Int J Pure App Biosci. 2013; 1 (3):1-6.

3. Grau V, Alcaniz M, Juan MC, Monserrat C, Knoll C. Automatic localization of cephalometric landmarks. J Biomed Informatics. 2001; 34:146-56.

4. Maina MB, Mahdi O, Kalayi GD. Craniofacial forms among three dominant ethnic groups of Gombe state, Nigeria. Int J Morphol. 2012; 30(1):211-6.

5. Patro S, Sahu R, Rath S. Study of cephalic index in Southern Odisha population. J Dent Med Sci. 2014; 13(1):41-4.

6. Vjdani Z, Bahmanpour S, Momeni S et al. Cephalometry in 14-18 years old girls and boys of Shiraz Iran high school. Int J Morphol. 2009; 27(1):101-4.

7. Anitha MR, Vijayanath V, Raju GM, Vijayamahantesh SN. Cephalic index of North Indian population. Anat Karnataka. 201 1; 5(1):40-3.

8. Shah S, Rathod SP, Patel SY, Singel TC, Pandya P. The study of cephalic index in living subjects in Gujarat region. Nat Integrated J Res Med. 2012; 3(4):54-6.

9. Shah GV, Jadhav HR. Study of cephalic index in students of Gujarat. J Anat Soci India. 2004; 53(1):25-6.

10. Golalipour MJ, Haidari K, Jahanshahi M, Farhani RM. The shapes of head and face in normal male newborns in South-East of Caspian sea. J Anat Soc India. 2003; 52(1):28-31.

11. Kondo S, Wakatsuki E, Shibagaki H. A somatometric study of the head and face in Japanese adolescents. Okajimas Folia Anat Jpn. 1999; 76(4):179-186.

12. Menenzes RG, Kanchan T, Srinivasan R, Uysal S. Cephalic index of Gurung community of Nepal. Kathmandu Univ Med J. 2005; 3(3):263-5.

13. Ilayperuma I. Evaluation of cephalic indices: A clue for racial and sex diversity. Int J Morphol. 2011; 29(1):112-7.

14. Staka G, Disha M, Dragidella F. Cephalic and facial indices among Kosovo-Albanian population. Int J Morphol. 2013; 31 (2):468-72.

15. Khair S, Bhandari D, Wavhal S. Study of cephalic index among the students of Mumbai region. Indian J Appl Res. 2013; 3(11):64-6.

16. Oladipo GS, Oluto JE, Suleiman Y. Anthropometric studies of cephalic indices of Ogonis in Nigeria. Asian J Med Sci. 2009; 1 (2):15-7.

17. Singh P, Purkait RA. Cephalometric study among sub caste groups Dangi and Ahirwar of Khurai block of Madhya Pradesh. Anthropologist. 2006; 8(3):215-7.

18. Odokuma El, Akpuaka FC, Igbigbi PS, Otuaga PO, Ejebe D. Patterns of cephalic indices in three west African populations. African J Biotechnol. 2010; 9(11):1658-62.

19. Maina MB, Mahdi O, Kalayi GD. Study of vertical and transverse cephalic indices in three ethnic groups of North-Eastern Nigerian origin. Trends Appl Sci Res. 2011; 6(11):1280-6.

20. Alves HA, Santos MIP, Melo FCL, Wellington R. Comparative study of cephalic index of populations from the regions of North and South of Brazil. Int J Morphol. 2011; 29(4):1370-4.

21. Salve MV, Thota M, Patibandla A. The study of cephalic index of Andra region (India). Asian J Med Sci. 201 1; 2(1):53-5. 